\title{
Validity in Assessment of Prior Learning
}

\author{
Bjarne Wahlgren, Vibe Aarkrog \\ Aarhus University, Aarhus, Denmark
}

\begin{abstract}
The article deals with the results of a study of school-based assessment of adults who have enrolled as students at a vocational college in order to qualify for occupations as skilled workers. Based on examples of methods for assessing the students' prior learning in a programme for hairdressers, the article discusses the need for specific criteria for assessment. The reliability and validity of the assessment procedures depend on whether the competences are well-defined, and whether the teachers are adequately trained for the assessment procedures.
\end{abstract}

Keywords: assessment, prior learning, adult education, vocational training, lifelong learning, validity

\section{Introduction}

Based on an empirical study of methods for assessment of prior learning (APL) ${ }^{1}$ in a vocational education and training (VET) program, the article discusses the requirements for qualified school-based APL. The focus is on APL in a specific VET programme that trains adults for skilled positions as hairdressers. APL is the first step in qualifying those who have already worked within this field for a number of years and who want to enrol as students at a VET college in order to obtain a formal qualification. Based on an assessment of the individual student's prior learning, a personal education and training plan is drafted, specifying the training that the student needs in order to obtain the qualification as a skilled hairdresser. This article focuses solely on APL.

APL has been studied internationally in various settings, including a substantial number of comparative studies concerning the organisation of APL in different countries (Andersson \& Stenlund, 2012; Harris, Breier, \& Wihak, 2011). Most of the studies focus on the organisational setting and the political background for APL, e.g., in relation to lifelong learning, employability, or economic, social, and cultural purposes (Andersen \& Laugesen, 2012; Halttunen, Koivisto, \& Billett, 2014, pp. 3-15). Few studies have focused on the actual process of assessment.

Wihak and Wong (2011) discussed different APL methods in a Canadian university context and concluded that "the predominant method to assess learning is the paper-based portfolio" (p. 317). Fejes and Andersson (2009) used the same procedure in a training programme for nurses. The nurses made "a self-assessment to estimate their own knowledge in a certain area" (Fejes \& Andersson, 2009, p. 47). Pokorny (2013) suggested that a combination of personal portfolios and dialogue improves the quality of the assessment process and

\footnotetext{
${ }^{1}$ In the literature, the concepts used to assess prior learning include recognition of prior learning (RPL), accreditation of prior experiential learning (APEL), prior learning assessment (PLA), prior learning assessment and recognition (PLAR), and validation of prior learning (VPL) (Andersson, Fejes, \& Sandberg, 2013, p. 405). In this article, assessment of prior learning (APL) is used to describe the assessment process and the outcome of the assessment.

Bjarne Wahlgren, Ph.D., professor, director, National Centre of Competence Development, Aarhus University.

Vibe Aarkrog, Ph.D., associate professor, Department of Education, Aarhus University.
} 
leaves the students with a more satisfying picture of the assessment process.

The present article presents and discusses the results from a project to develop criteria for assessing competences among adults who want to obtain the formal qualification as a hairdresser. In a broader perspective, the project sought to develop methods to obtain reliable and valid assessments of prior learning, also applicable in other areas than hairdressing. This article exemplifies how prior learning can be assessed in relation to the required competences for a skilled position.

\section{Theoretical Background}

"Prior learning" has been defined in different ways (Billett, Bound, \& Lin, 2014, p. 282). We define prior learning as the sum of all the individual's competences, i.e., competences achieved through formal learning, non-formal learning, and informal learning (European Centre for the Development of Vocational Training [CEDEFOP], 2009; Colardyn \& Bjørnåvold, 2004; European Council, 2012). As such, prior learning includes both school-based knowledge and practical experiences. In this article, we use the European Council's (2008) definition of competence: "Competence means the proven ability to use knowledge, skills and personal, social and/or methodological abilities, in work or study situations and in professional and personal development."

According to this definition, competence is a proven ability in a concrete situation within a particular area. A person is not competent in general and does not have competences at a general level; competences must instead be referred to specific contexts. In this article, the context is the VET programme' s curriculum, which outlines the competences that qualify for positions as skilled workers within hairdressing.

Pivotal in the definition of competence is the term "use," which is the ability to apply your knowledge, skills, and abilities signifying that APL should not only focus on the individual's knowledge and skills, but also on the individual's ability to perform in specific situations.

In relation to a given educational standard, APL raises some theoretical issues (Andersson \& Harris, 2006). One vital issue is the traditional relationship between "knowing how" and "knowing that" (Ryle, 1949). A great deal of a person's prior learning consists of knowing how, while the educational standard is more based on knowing that.

Another central issue concerns reliability and validity (Andersson, 2006). In a study of the reliability of APL in higher education, Stenlund (2011) compared different results of the assessment process over time and among different assessors. She concluded that the reliability is rather low, even though the criteria for assessment are quite specific. She concluded that "there is a need to take validity issues in APL seriously" (Stenlund, 2011, p. ii). In an empirical study of the translation of the heterogeneous skills among qualified immigrants who want to be integrated into the labour market, Diedrich (2013a; 2013b) highlighted the challenge of understanding complicated and comprehensive skills. Starr-Glass (2012) discussed validity and pointed out that the question is not only whether a particular performance resembles a particular course of study, but also whether the recognition of the candidate's work leads to a successful study, and eventually to a qualification (Starr-Glass, 2012). Later in this article, this is referred to as predictive validity.

Summing up, research points to different issues and problems in relation to assessing students' prior learning. A recurrent issue concerns the validity of the assessment. A key challenge in relation to validity is how to transform the results from the assessment of practical experiences (mainly based on knowing how) to the standards of curriculum-based knowledge (to a great extent based on knowing that). 


\section{Empirical Data}

The assessment process took place at a vocational college, and the assessors were all senior lectures at the college. During the research project, 36 students applied for assessment. The prospective students, who wanted to join the programme leading to a qualification as a hairdresser, had typically worked in low-skilled positions for a number of years. All the students completed the APL, however with differing results.

The data in this study include:

1. Observations of the student assessments. These observations focused on how the students are supported in describing and/or demonstrating their competences. Five students were interviewed afterwards.

2. Interviews with the four teachers who assessed the students. The purpose was to learn about the teachers' arguments for and considerations in relation to assessing the students' prior learning.

3. Written material containing different manuals and guidelines for the assessment.

4. A survey on the results of the different teachers' assessments.

The researchers observed students in five practical performance situations in the assessment process. In connection with the assessment, the students were asked how they interpreted the questions asked by the teachers.

Based on the observations, the teachers were interviewed about their impressions of the students' prior learning and their reflections on how they assessed the students' competences. The teachers were asked to outline their criteria for validation: What did they focus on when observing the student's performance? How can they tell whether or not the student possesses the particular competency? The interviews were semi-structured with open-ended questions. They were recorded and "vital sentences" were transcribed. "Vital sentences" are sentences that shed light on the criteria the teachers use for deciding whether the student possesses the competency or not.

\section{The Skilled Competency Profile}

The formal qualification for a skilled occupation includes a specific set of competences. These competences concern the ability to perform in various situations.

The APL is principally based on the competences outlined in the national regulations for qualified hairdressers, which contain a total of 15 competences. The five competences below exemplify what the qualified hairdresser should be able to do:

1. Apply technical theory relevant for the industry;

2. Apply "green" products, including background knowledge about green products;

3. Apply pivot point terminology, including comprehension of the underlying principles;

4. Perform haircutting, trimming, beard trimming, and shaving;

5. Work with all forms of advanced styling for both men and women, including modern styling.

The competences are formulated as actions. The qualified hairdressers should be able to apply something as part of their performance, and they should be able to accomplish actions at a certain level. The first three competences above are connected to applying, e.g., applying pivot point terminology or applying knowledge and concepts related to the occupation. The fourth and fifth competences, meanwhile, are connected to accomplish tasks, e.g., shaving.

Consequently, in order to assess which competences the individual possesses for accreditation in relation to a formal qualification as a hairdresser, the assessment instrument should be designed to assess the students' 
ability to apply knowledge that is relevant to the practical performance of tasks, as well as their ability to accomplish these tasks at a certain level.

\section{Assessment of Theoretical Knowledge}

Competence is based on knowledge. A person must have knowledge in order to act competently. In an educational setting, knowledge is often conceptualised as "theory" or theoretical knowledge. The competences in the hairdresser programme include, for example, theoretical knowledge about "technical terms" and "pivot point theory." The assessment of the student's theoretical knowledge is a central part of the APL. This theoretical knowledge includes "knowing that," "knowing why," and "knowing how."

In order to assess the student's level of theoretical knowledge, the student has to take a test that includes a number of questions about the following fields: colours and dyeing, terminology surrounding the cutting and perming of hair, and theory about hair biology.

The first type of question tests the student's knowing that, e.g., "What is...?" "What is the name of ...?" or "What does $\times x \times$ mean?" The questions will include: "The grainy pigmentation is?" "What is the pH of perm solution?" and "What does the term "distribution' mean?"

The second type of question deals with knowing why, i.e., explanations of things, for example, "Why do some people have a dry scalp?" "How can we explain that some men develop bald spots or are thin-haired?" and "How does insufficient nourishment affect the hair?"

The third and final type of question tests the student's knowing how and deals with actions and performances, including the meaning of various concepts related to the process, e.g., "Do you bleach dyed hair?" "How do you perform a pre-treatment?" and "What does it mean to perform an asymmetrical hair cut?"

The purpose in these tests is to ascertain the student's knowledge about the vocational field. Does the student know the technical terms? Does the student have knowledge about green products and the reasons for using these products? Does the student understand the principles for using the pivot point technique? etc.. The test of theoretical knowledge is based on a perception of what the qualified hairdresser should know, and the questions have been developed from the competences in the national curriculum, which concern the knowledge that the students should be able to apply when undertaking hairdressing tasks; please refer to the competences above.

The validity of the test depends on the student's perception of the included questions in the sense that the students should be able to understand the meaning of the questions and they should perceive the questions in the same way as the teachers who pose the questions. Thus, the challenge is to formulate the questions in terminology that is recognisable for the students. If the assessment is to be valid, the students must be able to transfer the concepts encountered in the test to their own work practice. As part of developing the test, the teachers have sought to refer to the students' practice in the questions; instead of merely using the terms and concepts from the school context, the teachers have referred to situations with which the students are supposed to have had practical experience. In addition, the teachers have gradually qualified the questions through feedback from the students. This has proved to be a success, as the results from the interviews with the students show that the students understand the meaning of the questions.

\section{Assessment of Competences}

In this article, "competence" is understood as the "ability to perform in specific situations." The hairdresser competences concern the ability to perform in situations related to the hairdresser profession. The hairdresser must be able to perform in relation to cutting, combing, dyeing, and shaving. 
A qualified hairdresser must be able to accomplish occupational tasks by applying relevant knowledge and performing with a certain amount of routine and confidence, resulting in products of a high standard. Accordingly, the APL of the students' competences should focus on three elements:

1. The students must demonstrate the ability to apply knowledge as part of accomplishing tasks;

2. The students must demonstrate the ability to accomplish tasks at a high level of quality;

3. The students must demonstrate a certain amount of routine and confidence in the work process.

In the project, the assessment of these three elements was based on observations of the students' performance in practical situations. The core of the APL included two days of practical performance where the students were expected to accomplish a number of tasks that corresponded to the tasks that required of a qualified hairdresser. The students are asked to demonstrate their abilities within haircutting, styling of long hair, wavy hairstyles and "bombage," and applying extensions and make-up. The students performed these tasks on either a mannequin or a human model.

\section{Assessment of the Ability to Apply Knowledge}

The teachers assessed the students' ability to apply theoretical knowledge during their practical performance. Based on a student's response in the written test and on the way the student performed the specific task, the teacher retested the student's knowledge by posing questions. The teacher might, for example, ask the student "Why do you keep your hand in a vertical position when you cut at the neck?" or "Which cutting technique are you using here?" The retest primarily provides knowledge about the extent to which the student is able to apply the correct concepts related to the performance of the task, and about whether the student can explain the reasoning for the choices made.

\section{Assessment of the Quality of the Task Performed}

Assessing whether the students possess the competences to perform specific tasks at a qualified level presupposes knowledge about what it means to perform the task at a qualified level. What does it mean to work with all forms of advanced styling for both men and women, including modern styling, at a qualified level? (Competence 5 above). It is not sufficient that the students can perform the tasks at hand; they should be able to perform the tasks to a certain level. In APL, the teachers have to assess how well or how qualified the students perform the tasks. However, determining whether or not a student is capable of performing a task at a qualified level is not enough. In an educational setting, it must be determined whether the student is "on the way"; i.e., the student can perform the task, however on a lower level than "qualified" or "perfect." Based on this knowledge, teachers are able to draft a precise training programme that will help the student gain precisely those competences required. To this end, the teachers have translated the competences into targets for each main subject within the training programme for hairdressers. They have categorised these targets into four levels: "Not competent," "Beginner," "Routine," and "Advanced." The developmental work has included drafting descriptions of the criteria for reaching a specific level. In the actual APL, the students should perform one task for each main subject.

The tasks have been chosen because they provide an opportunity for students to demonstrate their level of competence as they include a number of different skills. One of the tasks is combing "a wavy hairstyle" on a mannequin. Based on the student's performance, she will be assigned to one of the four aforementioned levels within hairstyling. Table 1 shows examples of the criteria for reaching Levels 1 till 3 within male hairstyling ("Not competent" corresponding to Level 0, applies to students failing to meet the criteria for Level 1). 
Table 1

Requirements for "Male Hairstyling"

\begin{tabular}{|l|l|}
\hline Level & Requirements \\
\hline Level 1: Beginner & $\begin{array}{l}\text { In the wavy hairstyle, curls should be shaped like crescents, twisting both clockwise and } \\
\text { counter-clockwise so as to form an S-shape. } \\
\text { The back of the cut must have a masculine form, which means a rectangular shape and not a round shape. } \\
\text { It is acceptable to have a few indents, some uneven and un-combed hair. }\end{array}$ \\
\hline Level 2: Practiced & $\begin{array}{l}\text { In the wavy hairstyle, curls should be shaped like crescents, twisting both clockwise and } \\
\text { counter-clockwise so as to form an S-shape. } \\
\text { A fixed number of waves must be found: Four of them should be visible from above and two waves } \\
\text { should be visible on each side. The waves must be parallel and follow the profile of the face. } \\
\text { The back of the cut must have a masculine form which means a rectangular shape and not a round shape. } \\
\text { It is not acceptable to have indents, some uneven and un-combed hair. }\end{array}$ \\
\hline Level 3: Advanced & $\begin{array}{l}\text { In the wavy hairstyle, curls should be shaped like crescents, twisting both clockwise and } \\
\text { counter-clockwise so as to form an S-shape. } \\
\text { A fixed number of waves must be found: Four of them should be seen from above and two waves should } \\
\text { be on each side. They must be parallel and follow the profile of the face. } \\
\text { The back of the cut must have a masculine form which means a rectangular shape and not a round shape. } \\
\text { It is not acceptable to have indents, some uneven and un-combed hair. } \\
\text { The student must complete the task within 25 minutes. } \\
\text { The student must demonstrate a high level of confidence in completing the task. }\end{array}$ \\
\hline
\end{tabular}

To be placed at the "Beginner" level, the student must be able to produce a male hairstyle where curls should be shaped like crescents, twisting both clockwise and counter-clockwise so as to form an S-shape and the back of the cut has a masculine form. To be placed at Level 2, "Practiced," there should be a fixed number of waves with a specific shape. No small flaws should appear. To be placed at Level 3, "Advanced," the hairstyle must have the same qualities as at Level 2; however, the student must finish the task within 25 minutes while demonstrating a high level of confidence. Based on these criteria for the standards of "male hairstyling," the teachers are able to place the performance at the right level.

In the interviews with the teachers, it became clear how they used these criteria in the actual assessment. The following examples can illustrate: A teacher places one of the students' performances below Level 1, arguing "The masculine form in the back is missing and is not sufficiently combed." Another performance is likewise placed at Level 1, with the teacher commenting "There are a different number of waves on each side. The waves are not appropriate in size. The combing lacks finish." Another performance is placed at Level 2 with the following remarks: "No major mistakes; however the performance lacks routine and speed." The teachers use various words to describe the performances; however, they apply the same taxonomy and the same criteria.

\section{Assessment of the Work Process}

As mentioned above, proficiency is part of the criteria developed for assessing the students' competence. In the example above, proficiency is among the criteria at Level 3. This kind of competence is not directly connected to the assessment of the quality of product (e.g., how good is the result of the "male hairstyling"); the concept is instead connected to the work process. The process should be fast and "demonstrate a high level of confidence."

In the targets developed for the other main subjects in the education program, similar concepts are used. For example, the student must "have an overview," "must show routine," or "must show self-confidence"; i.e., concepts describing the way the student should perform. Consequently, the assessment encompasses an assessment of the work process. How can the teachers ensure high validity when assessing these 
sub-competences? How can a teacher tell to which degree the task is performed confidently? What are the criteria for adequate "confidence"? In the project, we have worked with these issues. In the interviews, the teachers were asked to elaborate on the criteria they apply when assessing competences related to the work process. Based on their answers, we defined the various concepts, the concept "confidence" in relation to hairstyling, for example, is defined as "The comb and the brush should be handled correctly, allowing only few attempts to create the required amount of waves."

In a research perspective, it turned out that this process was necessary in order to obtain a certain amount of reliability among the teachers' different assessments. At the beginning of the project, the teachers had different perceptions of the concepts describing the quality of the work process. After a while, they gradually developed a mutual understanding of the assessment criteria. By defining the core content of these variables, the teachers became capable of performing assessments based on the same criteria.

As a by-product, this process sharpened the teachers' perceptions of quality, making the varying and often tacit knowledge visible to both the individual teacher and to the group of teachers as a whole, thereby enabling the teachers to discuss what they are doing and what they regard as a proficient performance.

\section{Discussion}

The main purpose of the study was to develop assessment tools that provide reliable and valid results. As such, the key question in determining the study's success is whether the methods developed improve the reliability and validity of the assessment.

The degree of reliability has been tested. As part of the project, we have studied inter-subjective reliability by comparing different teachers' assessments of the proficiency of the students' practical performance of tasks.

Four teachers individually assessed five different performances in three different disciplines: male hairstyle combing, female hairstyle combing, and male and female haircuts. As such, each teacher made 15 assessments. Of the total of 60 assessments, the teachers agreed on 48. Not surprisingly the teachers mostly agreed on the technical performances, while there was a greater diversity in their assessments regarding subjective issues, such as "style," "suitable to the shape of the head," and "the right hairstyle for the right person." The results correspond with the findings in a study by Stenlund. She concluded that "the intrarator reliability study revealed a higher agreement level than the interrator reliability study" (Stenlund, 2013, p. 545), meaning that assessors from the same institution used the same criteria (explicit or implicit) more often and were therefore more likely to agree than assessors from different institutions.

The figures for students' performance and progress further in the programme tell us that the assessments made by the teachers have a high predictive validity. This means that the students are actually able to pass their exam or journeyman's test after completing the training according to their individual educational plans.

"Concept validity" has been in focus in different parts of the project. To secure concept validity, it must be ensured that the students actually understand the concepts and the questions in the written test. Firstly, the questions have to be formulated in ways relatable to the students' actual practice. Secondly, the criteria for assessment must be logically derived from the formal qualifications set for the skilled occupation as hairdresser. Thirdly, the practical performance which is subject to assessment should be identical, or at least similar, to the performance of tasks in the actual hairdresser occupation.

The study shows that a reliable and valid assessment of competences requires two methods that supplement each other: a test of the students' knowledge in practice, and an assessment of the students' 
practical performances, including the performance of specific tasks. Performing specific tasks provides the assessor with an impression of the student's confidence, experience, and proficiency. The study likewise shows the importance of the practical performance in the assessment process when competence is understood as the application of knowledge, if the assessment of competences is to claim validity.

In further research, it should be studied whether the competences in current VET programmes are suited to school-based assessment, with regard to a distinction between production and service. The assessment methods are suitable for measuring production: Are the students able to produce a product (e.g., blow-drying, haircut, and hairstyle). However, this does not include an assessment of service, i.e., whether the students are able to treat customers in the right way. As such, the assessment method which has been developed places considerable emphasis on the quality of the product while downplaying the service aspects of the hairdressing situation. Assessing whether an individual can function as a skilled worker in areas where tasks produce a tangible result (e.g., as a carpenter, blacksmith, painter, or chef) the assessment may in principle be conducted by letting the student perform the tasks; for example, constructing a roof, forming a metal object, painting and wallpapering a room, or preparing a meal. The students are able to perform in the workshops at the VET college as they would do in the workplace, enabling their competences to be assessed in a school-based setting. However, in areas with a high degree of human contact (e.g., childcare, healthcare, or retail), it is difficult to establish a realistic everyday life situation at the VET college. The teachers have to simulate real practices, for example, by making the students play roles in simulated situations (Aarkrog \& Wahlgren, 2015). The hypothesis to be investigated is whereas competences related to production can be assessed in school, competences related to service should be assessed in the workplace. Hairdressing constitutes a fertile area for testing this hypothesis due to its dual nature: There is a tangible result, the haircut or the hairstyle as well as a high level of human interaction with customers.

Another issue concerns the assessors' (in this study, the teachers') competences. As mentioned in other studies, the ability to make correct and valid assessments requires specific competences (Halttunen \& Koivisto, 2014; Hamer, 2010; Van Berkel, 2014). The assessors (the teachers) should be able to translate knowledge and observed performances into competences. They must have knowledge of the specific job functions and tasks within the occupation in its contemporary form(s), as well as knowledge about the content of the VET programme curriculum. Furthermore, they should be able to use the results of the assessment process to develop a suitable training programme. In the present study, we found that the teachers' ability to make valid assessments was strengthened over the course of the project. The teachers developed assessment competences. It seems reasonable to conclude that a fair and valid assessment process requires the assessors to develop specific competences.

\section{Conclusion}

The study of APL in a school-based setting shows that the combination of written tests and observation of the students' performance of practical tasks makes it possible to determine the students' competences. Based on the empirical data, two issues have been raised and analysed.

The first issue concerns the teachers' interpretation of the competences outlined in the national curricula of the VET study programmes. The teachers have to know which competences are required to be a professional practitioner in skilled occupations, and they should also know how to assess these competences.

The second issue concerns the reliability and validity of the assessment procedures. The study shows that 
the teachers seek to strengthen validity and reliability by detailing the criteria for the assessment. In this process, it is important to distinguish between the students' practical and theoretical knowledge, the students' ability to apply this knowledge, the students' ability to accomplish relevant tasks in the occupation at a high level, and the students' way of performing these tasks.

The study shows that practice-based competences can be assessed at school with high validity, however, under the following specific conditions: The required competences should be well-defined, precise, and operative, and the assessors (the teachers) should possess specific assessment competences.

\section{References}

Aarkrog, V., \& Wahlgren, B. (2015). Assessment of prior learning in adult vocational education and training. International Journal for Research in Vocational Education and Training, 2(1), 39-38.

Andersen, M., \& Laugesen, C. (2012). Recognition of prior learning within formal adult education in Denmark. PLAIO-Prior Learning Assessment, 1(2).

Andersson, P. (2006). Different faces and functions of RPL: An assessment perspective. In P. Andersson, \& J. Harris (Eds.), Re-theorising the recognition of prior learning. Leicester: National Institute of Adult Continuing Education.

Andersson, P., \& Harris, J. (2006). Re-theorising the recognition of prior learning. Leicester: National Institute of Adult Continuing Education.

Andersson, P., \& Stenlund, T. (2012). Nordisk forskning och exempel på validering (Nordic research on validation of prior learning). Oslo: NVL/VOX.

Andersson, P., Fejes, A., \& Sandberg, F. (2013). Introducing research on recognition of prior learning. International Journal of Lifelong Education, 32(4), 405-411.

Billett, S., Bound, H., \& Lin, M. (2014). Recognising and certifying workers' knowledge: Policies, frameworks and practices in prospect: Perspectives from two countries. In T. Halttunen, M. Koivisto, \& S. Billett (Eds.), Promoting, assessing, recognizing and certifying lifelong learning. Dordrecht: Springer.

Colardyn, D., \& Bjørnåvold, J. (2004). Validation of formal, non-formal and informal learning: Policy and practices in EU member states. European Journal of Education, 39(1).

Diedrich, A. (2013a). Translating validation of prior learning in practice. International Journal of Lifelong Education, 32(4), 548-570.

Diedrich, A. (2013b). "Who's giving us the answers?" Interpreters and the validation of prior foreign learning. International Journal of Lifelong Education, 32(2), 230-246.

European Centre for the Development of Vocational Training (CEDEFOP). (2009). European guidelines for validating non-formal and informal learning. Luxembourg: Office for Official Publications of the European Communities.

European Council. (2008). Recommendation of the European Parliament and the Council of 23 April 2008 on the establishment of the European Qualifications Framework for lifelong learning (Annex 1). Brussel: European Council.

European Council. (2012). Council recommendation on the validation of non-formal and informal learning of 20 December 2012. Brussel: European Council.

Fejes, A., \& Andersson, P. (2009). Recognising prior learning: Understanding the relation among experiences, learning and recognition from a constructivist perspective. Vocation and Learning, 2(1), 37-55.

Halttunen, T., \& Koivisto, M. (2014). Professionalisation of supervisors and RPL. In T. Halttunen, M. Koivisto, \& S. Billet (Eds.), Promoting, assessing, recognizing and certifying lifelong learning. Dordrecht: Springer.

Halttunen, T., Koivisto, M., \& Billett, S. (Eds.). (2014). Promoting, assessing, recognizing and certifying lifelong learning - International perspectives and practices. London: Springer.

Hamer, J. (2010). Recognition of prior learning-Normative assessment or co-construction of preferred identities? Australian Journal of Adult Learning, 50(1).

Harris, J., Breier, M., \& Wihak, C. (Eds.). (2011). Researching the recognition of prior learning-International perspectives. Leicester: International Institute of Adult Continuing Education.

Pokorny, H. (2013). Portfolios and meaning-making in the assessment of prior learning. International Journal of Lifelong Education, 32(4), 518-534. doi:10.1080/02601370.2013.778076

Ryle, G. (1949). The concept of mind. London: Hutchinson. 
Starr-Glass, D. (2012). Partial alignment and sustained tension: Validity, metaphor and prior learning assessment. PLAIO-Prior Learning Assessment, 1(2).

Stenlund, T. (2011). As valid as it can be? Assessment of prior learning in higher education (Doctoral dissertation, Umeå University).

Stenlund, T. (2013). Agreement in assessment of prior learning related to higher education: An examination of interrater and intrarater reliability. International Journal of Lifelong Education, 32(4), 535-547.

Van Berkel, A. (2014). Securing assessors' professionalism: Meeting assessor requirements for the purpose of performing high-quality (RPL) assessments. In T. Halttunen, M. Koivisto, \& S. Billet (Eds.), Promoting, assessing, recognizing and certifying lifelong learning. Dordrecht: Springer.

Wihak, C., \& Wong, A. (2011). Research into prior learning assessment and recognition (PLAR) in university adult education programmes in Canada. In J. Harris, M. Breier, \& C. Wihak (Eds.), Researching the recognition of prior learning. Leicester: National Institute of Adult Continuing Education. 